\title{
Investigating the issue of copyright and security measures in digital libraries
}

\author{
Sedigheh Ahmadi Fasih"
}

Document research and Conservation Department, Faculty member (Instructor), National Library \& Archives of I.R of Iran, P.O. Box: 1548613111

\section{H R O N I C L E}

Article history:

Received May 12, 2013

Received in revised format

12 August 2013

Accepted 28 September 2013

Available online

October 52013

Keywords:

Copyright

Digital libraries

Security

\section{A B S T R A C T}

\begin{abstract}
During the past few years, digital libraries have been the primary source of retrieving necessary information. IT helps many scholars have the access to recently published value added researches around the world. However, information security and copyright concerns are among the most important issues and there must be good rules and regulation to protect authors against any sort of copyright violation. In this paper, we present an empirical investigation to find out about the status of copyright issues in one of Iranian libraries. The proposed study of this paper designs a questionnaire in Likert scale and distributes it among 96 librarian experts. Cronbach alpha is equal to 0.76 , which is well above the minimum acceptable level. The results of our investigation indicate that although expert believe the status of copyright is in desirable level when the level of significance is five percent, there are some concerns on some issues. In other words, experts believed that all copyrights are not well protected and digital libraries do not follow governmental rules and regulation on fully protecting authors' rights. In addition, experts believed that the security of sources available on digital libraries is not well protected.
\end{abstract}

\section{Introduction}

During the past two decades, there have been tremendous changes on information technology (Arcand, 2000; Barkley, 2001). Many people are able to have the access to many scientific materials through websites and search engines from home and it is getting easy to learn more about what they need. One of the most important issues on digital libraries is associated with copyright issues and there have been various efforts on protecting people's rights. DLs try to ease the access to content over computer and communication networks, and digitization could be taken as a visible proposition to enhance the shelf life of non-digital content by preservation apart from the virtue of increased and easy access, thereby furthering usage. DLs are viewed in various perspectives and DLs is the single most development that

*Corresponding author. Tel: (+98) $2122900270-1$ 
has brought about sweeping changes in the library and information discipline presently in the developed world (Calhoun, 2002; Jeevan, 2004).

Advancements in computer and information technology with breakthroughs in memory technology has not only reduced the necessary infrastructure expenses for hosting digital libraries, but the demonstrated success of a wide variety of projects in western countries also endorsed the chances of their survival even in a developing country. Though the professionals and libraries in different developing countries are also experiencing the value of Internet, and electronic information highways. DL development needs to be considered as an additional task to populate the web sites with valuable in-house content like the research reports, publications of in-house researchers, etc. DL projects and developments in the country are so many, though a number of them are only at a preliminary stage. The digital library development in many countries needs a two-pronged strategy (i) to digitize local content, and (ii) to devise options for achieving external resources. Channels for internal content include scientific journals and serials for research, conference proceedings, theses and dissertations and preprints, research and status reports, textbooks and learning materials, government publications, spiritual/heritage sources, tourism information, traditional knowledge, etc. In terms of external resources, there are electronic various options from publishers and information providers such as, online access through Web of subscribed journals, CDs and floppies containing supplementary material of printed books, bibliographic/full-text databases, which could be hosted on library servers or intranet along with local content (Jeevan, 2004; Shen et al., 2008).

Maidabino and Zainab (2012) presented a framework called "house model" to build a tool to evaluate collection security implementation in university libraries. In their survey, the factors and items are obtained from published literature on library security and library collection security issues. They presented five factors including collection security governance; operations and processes; people issues; physical and technical aspects of collection security and the security culture in the libraries. They examined their model on 61 senior and professional librarians from four Nigerian universities.

The number of DLs accessible over the Open Archives Initiative-Protocol for Metadata Harvesting (OAI-PMH) has been steadily increasing over the past years. Earlier attempts in the DL area have concentrated on metadata harvesting and distributing value-added Federated Digital Library (FDL) services to the users. FDL services, nevertheless, need to meet significant performance and scalability requirements, which is difficult to reach in centralized metadata harvesting systems. Trnkoczy, J., \& Stankovski, V. (2008) evaluated the advantages of using Web Services Resource Framework (WSRF) compliant grid middleware infrastructure for providing FDL services. The presented FDL application permits for parallel harvesting of OAI-PMH compliant DLs. They reported that this approach could efficiently solve the performance related problems, while it also contributed to bigger flexibility of the system. The quality of service was improved as metadata could be updated frequently, and the system did not show any single point of failure.

Arif and Kanwal (2009) investigated the acceptance and relative importance of DLs among female students of International Islamic University, Islamabad, Pakistan. The study also highlighted the problems confronted by the female students in completing their research work after limited access to DL in the female campus of the University. They reported that the access to DL was indispensable to the students to finish their research work. With limited access to the DL, the students could not meet their information requirements from the Internet and the libraries of other universities. The quantity as well as quality of their research work were influenced due the restriction of digital resources. In addition, the limited access influenced adversely to improve insight of the respondents regarding technological developments in their respective area of research.

Shuva (2012) described the ways applied to build digital libraries in Bangladesh as well as the problems, which might be faced during DLs development. The survey reported the existing status of 
DL development, specifically the status of digitization in Bangladesh as well as government initiatives to build digital library system.

\section{The proposed model}

We present an empirical investigation to find out about the status of copyright issues in one of Iranian libraries. The population of this survey includes all managers who work for DLs in city of Tehran, Iran. Therefore, we may use the following formula to calculate the minimum number of sample size,

$$
n=\frac{N \times z_{\alpha / 2}^{2} \times p \times q}{\varepsilon^{2} \times(N-1)+z_{\alpha / 2}^{2} \times p \times q},
$$

where $N$ is the population size, $p=1-q$ represents the yes/no categories, $z_{\alpha / 2}$ is CDF of normal distribution and finally $\varepsilon$ is the error term. Since we have $p=0.5, z_{\alpha / 2}=1.96$ and $N=200$, the number of sample size is calculated as $n=96$. The proposed study of this paper designs a questionnaire in Likert scale and distributes it among 96 librarian experts. Cronbach alpha is equal to 0.76, which is well above the minimum acceptable level. After collecting the necessary information, we have used Chi-Square test to verify all 20 questions of the survey and Table 1 summarizes the results of our findings.

\section{Table 1}

The summary of Chi-Square test on various questions

\begin{tabular}{|c|c|c|c|c|c|c|}
\hline \multirow{2}{*}{ Row } & \multicolumn{5}{|c|}{ Frequency } & \multirow[t]{2}{*}{ Chi-Square } \\
\hline & Completely disagree & Disagree & No opinion & Agree & Completely agree & \\
\hline 1 & 15 & 5 & 19 & 36 & 18 & $48.167^{*}$ \\
\hline 2 & 18 & 12 & 2 & 54 & 7 & $637.561^{*}$ \\
\hline 3 & 3 & 23 & 23 & 34 & 10 & $79.808^{*}$ \\
\hline 4 & 35 & 34 & 10 & 11 & 3 & $123.150^{*}$ \\
\hline 5 & 3 & 13 & 10 & 47 & 20 & $144.960^{*}$ \\
\hline 6 & 14 & 16 & 8 & 12 & 43 & $48.672^{*}$ \\
\hline 7 & 48 & 12 & 10 & 17 & 6 & $193.772^{*}$ \\
\hline 8 & 14 & 16 & 15 & 40 & 8 & $44.505^{*}$ \\
\hline 9 & 7 & 14 & 11 & 55 & 6 & $167.737^{*}$ \\
\hline 10 & 11 & 6 & 7 & 54 & 15 & $113.672^{*}$ \\
\hline 11 & 35 & 17 & 13 & 25 & 3 & $102.662^{*}$ \\
\hline 12 & 11 & 13 & 7 & 58 & 4 & $140.667^{*}$ \\
\hline 13 & 39 & 35 & 2 & 12 & 5 & $113.217^{*}$ \\
\hline 14 & 2 & 38 & 30 & 22 & 1 & $119.177^{*}$ \\
\hline 15 & 8 & 12 & 5 & 57 & 11 & $157.308^{*}$ \\
\hline 16 & 3 & 7 & 6 & 61 & 6 & $71.803^{*}$ \\
\hline 17 & 25 & 9 & 5 & 50 & 4 & 81.404* \\
\hline 18 & 6 & 39 & 9 & 35 & 4 & $64.530^{*}$ \\
\hline 19 & 3 & 45 & 35 & 8 & 2 & $124.606^{*}$ \\
\hline 20 & 24 & 30 & 22 & 15 & 2 & $49.934^{*}$ \\
\hline
\end{tabular}

The results of Table 1 indicate except three cases, 7, 11 and 13, in all other cases, experts confirmed that customers agreed that the DLs located in Tehran, Iran have been able to protect authors' right. However, in three cases, they did not confirm the results of our survey. In other words, the results of our investigation have indicated that the status of copyright has been in desirable level when the level of significance was five percent. In other words, experts believed that all copyrights were not well protected and digital libraries have not followed governmental rules and regulation on fully protecting authors' rights. In addition, experts believed that the security of sources available on digital libraries has not well protected.

We have performed one-way t-student test to examine the overall performance of the DLs in Tehran and Table 2 summarizes the results of our survey. 


\section{Table 2}

The summary of t-student

\begin{tabular}{cccccc}
\hline Number & Mean weight & Mean difference & t-value & df & Sig. \\
\hline 93 & 3.06944 & 0.06944 & $3.079^{*}$ & 92 & $\mathrm{p}>0.034$ \\
\hline
\end{tabular}

As we can observe from the results of Table 2, the average weight of scores given to questions is equal to 3.06944 and the result is statistically significance.

\section{Conclusion}

In this paper, we have presented an empirical investigation about the status of copyright issues in one of Iranian libraries. The proposed study of this paper designs a questionnaire in Likert scale and distributes it among 96 librarian experts. The results of our investigation have indicated that although expert believed the status of copyright was in desirable level when the level of significance was five percent, there were some concerns on some issues. In other words, experts believed that all copyrights were not well protected and digital libraries did not follow governmental rules and regulation on fully protecting authors' rights. In addition, experts believed that the security of sources available on digital libraries was not well protected.

\section{References}

Arcand, J. (2000). Security and the digital library: a look at authentication and authorization issues. Library Collections, Acquisitions, and Technical Services, 24(2), 344-346.

Arif, M., \& Kanwal, S. (2009). Acceptance of digital library among female students and effects of limited access of digital library on their performance in research work: A case of International Islamic University. The International Information \& Library Review, 41(3), 122-128.

Barkley, D. (2001). The Digital National Security Archive: The Documents That Made U.S. Policy: The National Security Archive National Security Archive, The Gelman Library, George Washington University, Washington, DC 20037. Journal of Government Information, 28(1), $115-$ 117.

Calhoun, K. (2002). From information gateway to digital library management system: a case analysis. Library Collections, Acquisitions, and Technical Services, 26(2), 141-150.

Jeevan, V. K. J. (2004). Digital library development: identifying sources of content for developing countries with special reference to India. The International Information \& Library Review, 36(3), 185-197.

Maidabino, A. A., \& Zainab, A. N. (2012). A holistic approach to collection security implementation in university libraries. Library Collections, Acquisitions, and Technical Services, 36(3), 107-120.

Trnkoczy, J., \& Stankovski, V. (2008). Improving the performance of Federated Digital Library services. Future Generation Computer Systems, 24(8), 824-832.

Shen, R., Vemuri, N. S., Fan, W., \& Fox, E. A. (2008). Integration of complex archeology digital libraries: An ETANA-DL experience. Information Systems,33(7), 699-723.

Shuva, N. Z. (2012). Building digital libraries in Bangladesh: A developing country perspective. The International Information \& Library Review, 44(3), 132-146. 